\title{
Impact of low fertility and early age at sterilisation on women's formal education and skill development in South India
}

\author{
Saseendran Pallikadavath ${ }^{1,2}$ - S Irudaya $\operatorname{Rajan}^{3}$ • \\ Chris Wilson ${ }^{4}$
}

Published online: 12 May 2016

(C) The Author(s) 2016. This article is published with open access at Springerlink.com

\begin{abstract}
This paper examines the impact of low fertility and early age at sterilisation on women's formal education and skill development in South India. Multilevel ordered-logit modelling of pseudo-cohort data re-organised from the three rounds of National Family Health Survey, and thematic analysis of qualitative data collected from Tamil Nadu and Kerala states showed no evidence of women's resumption of formal education or uptake of skill development training in the poststerilisation and post-childcare period. While resuming formal education in the poststerilisation and post-childcare period is harder to achieve for various individual, household, community and policy reasons, there is greater preparedness and support for women to undertake skill development training. As low fertility and early age at sterilisation are widely regarded as the emerging reproductive norm in India, poststerilisation and -childcare women will be a significant population group both in number and in proportional terms. No government policies or programs have so far recognised this group. India's new government should consider targeted skill development programs for post-sterilisation and -childcare women appropriate to their social, economic and educational levels. An important contribution of the family planning program, particularly female sterilisation, for the economic and social development of the family and the wider society will otherwise be lost.
\end{abstract}

Saseendran Pallikadavath

sasee.pallikadavath@port.ac.uk

1 Portsmouth-Brawijaya Centre for Global Health, Population and Policy, University of Portsmouth, Portsmouth, United Kingdom

2 Portsmouth-Brawijaya Centre for Global Health, Population and Policy, University of Brawijaya, Malang, Indonesia

3 Centre for Development Studies, Trivandrum, India

4 Nuffield College, University of Oxford, Oxford, United Kingdom 
Keywords India $\cdot$ Developing countries $\cdot$ Low fertility $\cdot$ Women $\cdot$ Education $\cdot$ Skill development $\cdot$ Education policy

\section{Introduction}

Most of the countries in the world today have access to some form of family planning services (Cleland 2009; Seletzer 2002). In 2009, of the 1179 million couples (married or in a union in the age group 15-49 years) in the world, 660 million couples $(56 \%)$ have used modern family planning methods (United Nations 2011). Among the modern family planning methods, female sterilisation has been the most popular family planning method. Globally, in 2009, about 223 million women were sterilised; this is about $19 \%$ of all couples and $34 \%$ of modern family planning users. In the less developed regions, about $21 \%$ of women were sterilised in 2009, compared to $8 \%$ in the more developed world. In South Asia this percentage was $29 \%$. Thus, female sterilisation is the principal family planning method in South Asia and higher in this region than in any other region in the world except Central America, where $34 \%$ of the couples had used sterilisation in 2009 (United Nations 2011).

In South Asia, India has the highest percentage of couples using female sterilisation. Indeed, India is one of the few countries in the world where female sterilisation is adopted by over one-third of the couples, and it accounts for about two-thirds of modern contraceptive users [International Institute for Population Sciences (IIPS) and Macro International 2007]. In India, sterilisation as a contraceptive method was launched in 1966, but was dominated by male sterilisations until the late 1970s. For example, during the 1970s, only $2.6 \%$ of the couples had used female sterilisation (3.5\% male sterilisation) and there was greater emphasis on male sterilisation provided through the sterilisation camps (Krishnakumar 1974). This was the case particularly during the Indian Emergency, a 21-month period (1975-1977) when Prime Minister Indira Gandhi unilaterally advised the president to declare a state of emergency across the country. During the Emergency period 8.4 million sterilisations were carried out and about $75 \%$ of those were male sterilisations (Gwatkin 1979). It was only during the 1980s that female sterilisation started to become a popular family planning method primarily due to the setback of coercive vasectomy camps conducted during the Emergency period (Basu 1985). Other factors that contributed to this shift were the development of laparoscopic techniques, widespread dissatisfaction with vasectomy due to side effects, the introduction of women-centred health programs such as the Reproductive and Child Health $(\mathrm{RCH})$ program following the International Conference on Population and Development (ICPD), and cash incentives for family planning users (National Population Stabilisation Fund 2007). Although method-specific contraceptive targets were removed in 1996 (Srinivasan 1998; Donaldson 2002), the emphasis on female sterilisation continued unabated (BBC 2011). In 2005-2006 about $37 \%$ of couples had used female sterilisation compared to just $1.0 \%$ male sterilisation (International Institute for Population Sciences and Macro International 2007). Thus, not only has the percentage of sterilised women increased in the last 
three decades but also their proportion within modern contraceptive users. There is no evidence that this trend will change in the future despite recent efforts to encourage male sterilisations (One India 2011).

There has been important inter-regional and inter-state variation in the use of female sterilisation in India. Sterilisation acceptance has been higher in Southern states compared to northern states. For example, in Uttar Pradesh, one of the north Indian States, only about $17 \%$ of women used sterilisation in 2005-2006 compared to $63 \%$ in Andhra Pradesh; $57 \%$ in Karnataka; $55 \%$ in Tamil Nadu; and $49 \%$ in Kerala. In the southern states there has been a significant increase in the percentage of sterilised women. For example, in Andhra Pradesh, there has been a 25 point increase in the percentage of women using female sterilisation between 1992-1993 and 2005-2006 (IIPS and Macro International 2007).

Yet another important feature of female sterilisation in India is that it occurs at younger ages and with fewer numbers of children than elsewhere (Singh et al. 2012). Further, there has been a decline in female age at sterilisation in the last few decades. For example, the median age at sterilisation declined from 26.6 years in 1992-1993 to 25.5 in 2005-2006 (IIPS and Macro International 2007). During this period the total fertility rate (TFR) declined from 3.36 to 2.66 children per woman. Data from some of the Southern Indian States, where the fertility transition began earlier than in the rest of India, revealed a significant decline in age at sterilisation and an increased pace in fertility decline. In Andhra Pradesh, for example, the median age at sterilisation declined from 24.5 years in 1992-2003 to 23.3 years in 2005-2006. During this period the TFR declined from 2.67 to 1.82 (IIPS and Macro International 2007).

The above pattern of sterilisation provides women with many years free of reproduction. In India, on average, by the time a sterilised woman reaches 60 years of age she would have spent about 30-35 years reproduction-free; in southern states like Andhra Pradesh this would be even higher. With low fertility, these women will be shouldering fewer child-related responsibilities compared to higher fertility women. Thus, early age at sterilisation and low fertility provides women with opportunities in terms of time which otherwise would have been occupied by reproduction and child care activities. Although family planning programs in India began in 1951 (Ledbetter 1984) and female sterilisation has been an important method of family planning since the 1980s, no research has so far examined its impact on women's education and skill development. Studies have provided information about educational levels of sterilised women (Dreze and Murthi 2001; McNay et al. 2003; Bhandari and Smith 1997). Health and other benefits of sterilisation (Cleland et al. 2012) were identified as both an outcome and rationale (Ross and Smith 2011; Seletzer 2002) for implementing family planning programs in the developing countries. There is an urgent and important need to examine the impact on women's education and skill development in the post-sterilisation context as this will help policy planners to take measures to utilise this significant human resource. Given the context, the aim of this paper is to examine whether low fertility and early age at female sterilisation enable women to resume formal education and/or skill development in the post-sterilisation and -childcare period and to understand individual, household, and community level factors that facilitate 
or hinder such progression using a mixed methods approach (Brannen 2005). The focus of this study is South India, given its persistent low fertility and early age at sterilisation.

\section{Data and methods}

\section{Quantitative data and methods}

This paper uses data from the three rounds of the National Family Health Survey (NFHS) conducted during 1992-1993 (NFHS-1); 1998-1999 (NFHS-2); and 2005-2006 (NFHS-3) (IIPS and ORC Macro 2000; IIPS and Macro International 2007; IIPS 1995). As the focus of this paper is South India, the data from Andhra Pradesh, Karnataka, Kerala, Goa and Tamil Nadu were used for analysis. NFHS are national sample surveys that adopted a uniform sampling strategy and hence the findings are generalisable to the respective geographic areas such as states and regions. Majority of the variables selected for the analysis in this paper were taken from the women's survey (a survey of currently married women in the age group 15-49 years) component. The details of the survey design and other details are given in the three reports (IIPS and Macro International 2007; IIPS and ORC Macro 2000; IIPS 1995).

Figure 1 shows the pseudo-cohort framework used to study women's educational progression subsequent to their adoption of sterilisation. From the merged data set of the three surveys, two sterilisation cohorts were generated for the analysis according to the year of sterilisation: 1986-1991 and 1992-1997. These cohorts have been identified in order to accommodate data from all three surveys and maximise data use. The first sterilisation cohort was interviewed during 1992-1993 (reference year within 1-7 years of sterilisation); 1998-1999 (after 7-13 years of sterilisation); and 2005-2006 (after 14-20 years of sterilisation). The second cohort

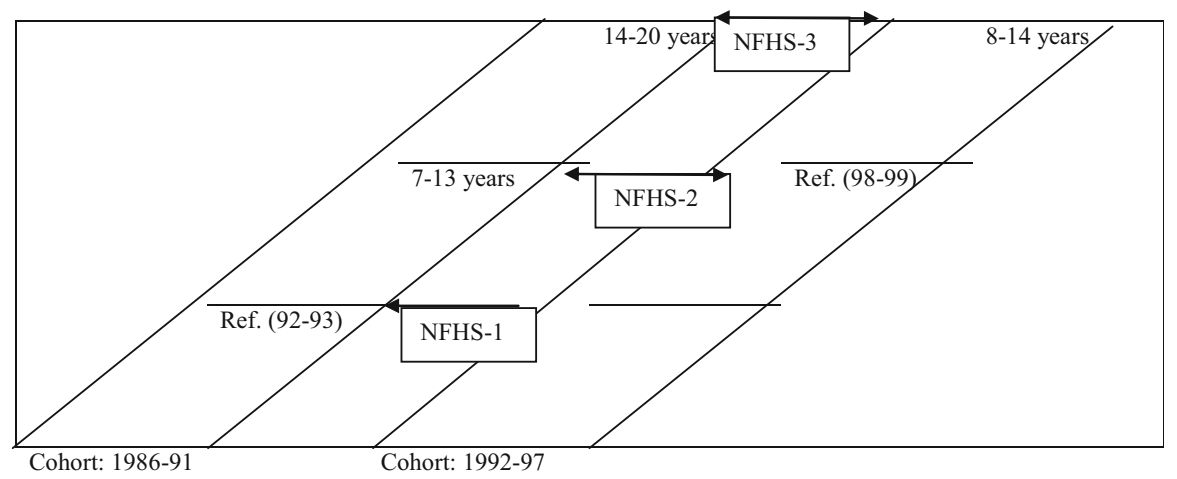

Fig. 1 Pseudo-cohort framework to analyse educational progress among sterilised women using three cross-sectional surveys 
was interviewed in 1998-1999 (within 1-7 years of sterilisation) and 2005-2006 (after 8-14 years of sterilisation). It is assumed that within the first 1-7 years women may not resume formal education or training due to child care responsibilities and we therefore consider the period beyond 7 years to be the poststerilisation and -childcare period. As the three surveys were cross-sectional, the cohorts at the three survey points were not made up of the same women and thus are called pseudo-cohorts.

The percentages of women in each sterilisation cohort according to educational levels are given in Table 1. The total samples for 1986-1991 and 1992-1997 were 7456 and 6739 respectively. In order to study the impact of early sterilisation and low fertility on women's education each sterilisation cohort was further divided into: (1) sterilised below 25 years of age (2) sterilised between 25 and 29 years (3) sterilised at 30 or above years of age (4) sterilised with 1-2 children and (5) sterilised with 3 or more children. Combinations of age and fertility were tried but due to small numbers such analysis had to be abandoned.

The next step in the analysis was to study whether or not educational levels have improved in the post-sterilisation and -childcare period after controlling for the effects of co-variates and clustering. Thus, the objective of this analysis was to examine whether or not educational levels have improved for the 1986-1991 sterilisation cohort in 1998-1999 and 2005-2006 compared to 1992-1993 (reference year). For the 1992-1997 sterilisation cohort the reference year was 1998-1999 and the comparison year was 2005-2006. In order to achieve this objective multilevel ordered logit modelling was considered the most suitable statistical method considering the ordered nature of the dependent variable (educational level of women), i.e.: $0=$ no education; $1=$ primary; 2 secondary and higher. Multilevel modelling offers a mechanism for measuring the influence of unobserved community effects on outcome variables. It also provides a robust method for analysing hierarchically clustered data by accounting for nonindependence of observations within the clusters (Goldstein 2010). In the model, different survey points were considered as a time variable and the covariates controlled for in the analysis are age at marriage, husband's education, caste,

Table 1 Number and percentage of women with various educational levels according to sterilisation cohorts and year of survey, South India

\begin{tabular}{|c|c|c|c|c|c|}
\hline \multirow[t]{2}{*}{ Education } & \multicolumn{3}{|c|}{$\begin{array}{l}\text { Sterilisation cohort } \\
1986-1991 \\
\mathrm{~N}=7456\end{array}$} & \multicolumn{2}{|c|}{$\begin{array}{l}\text { Sterilisation cohort } \\
1992-1997 \\
\mathrm{~N}=6739\end{array}$} \\
\hline & 1992-1993 (R) & 1998-1999 & 2005-2006 & 1998-1999 (R) & 2005-2006 \\
\hline No education & $1382(42)$ & $750(43)$ & $906(38)$ & $1035(38)$ & $1217(41)$ \\
\hline Primary & $1032(31)$ & $505(29)$ & $754(32)$ & $536(20)$ & $584(19)$ \\
\hline Secondary and above & $910(27)$ & $498(28)$ & $719(30)$ & $1128(42)$ & $1185(40)$ \\
\hline
\end{tabular}

$R$ Reference category 
religion, state and place of residence. The cluster levels included in the analysis are individual (level 1) and Primary Sampling Unit (level 2). Five models were generated for each sterilisation cohort resulting in a total number of 10 models: Model 1, women sterilised below 25 years; Model 2, women sterilised between 25 and 29 years; Model 3, women sterilised at 30 year or more; Model 4, women sterilised with 1-2 children and Model 5, women sterilised with 3 more children. Analyses were carried out in STATA MP11 (StataCorp 2009).

\section{Qualitative data and methods}

The quantitative data discussed above have many limitations. To explain why women could or could not improve their formal education following sterilisation and child care responsibilities it was necessary to gather qualitative data also. Qualitative data focused on individual, household and community level factors that are conceptually associated with women's resumption of education and skill development. Qualitative data were collected from two Southern Indian states of Tamil Nadu and Kerala. These two states were selected as they had low fertility for a long period of time. For example, Kerala and Tamil Nadu experienced belowreplacement fertility (i.e. below 2.1 children) over 20 and 10 years, respectively (Rajna et al. 2005). From the two states one district each with lowest fertility was selected. These districts are Pattanamthitta (Government of India 2012) from Kerala and Thirunelveli (National Informatics Centre 2013) from Tamil Nadu. One village each was selected from these districts based on existing contacts. Data collection followed a systematic protocol adopted in qualitative research including ethical approvals. In the first instance, the principle researcher of the project contacted a Village Panchayat (Local Government) member and explained the project and the support needed for fieldwork. Researchers were then introduced to the Integrated Child Development Services (ICDS) workers in the villages. Researchers met a group of ICDS worker in the village Panchayat office and explained the study and characteristics of sterilised women required for interviews. ICDS workers knew the sterilisation status of the majority of women in the village through their maternal and child health programs. They contacted potential women with details of the research and sought their willingness to participate in the study. Women in turn discussed the study with their husbands and in-laws and reported to ICDS workers that they could pass on their consent to the research staff. Research staff then contacted women and discussed the project and obtained written consent. In total 50 women were interviewed in this study from 50 households; 25 each from Pattanamthitta and Thirunelveli. In addition to sterilised women, 15 husbands, 5 inlaws and 2 community members were interviewed. Women and men were interviewed by female and male interviewers respectively, using an interview guide. All the interviews were conducted at respondents' homes. All the interviews were carried out in local language and were audio recorded. Transcribed data were analysed for themes using Nvivo 9 (QSRInternational 2010) package. Characteristics of women interviewed in the study are given in Table 2. 
Table 2 Characteristics of women interviewed, Kerala and Tamil Nadu

\begin{tabular}{|c|c|c|}
\hline $\begin{array}{l}\text { Sample characteristics, women and their } \\
\text { households }\end{array}$ & Pathanamthitta & Thirunelveli \\
\hline Average duration of schooling & 11 years & 5 years \\
\hline Average age at the time of interview & 45 years (range $30-58$ ) & 45 years $(32-58)$ \\
\hline Average age at sterilisation & 27 years & 28 years \\
\hline Average number of children at sterilisation & 2 & 3 \\
\hline Religion & Hindu, Muslim and Christian & $\begin{array}{l}\text { Hindu, Muslim and } \\
\text { Christian }\end{array}$ \\
\hline Average age at marriage & 22 years & 20 years \\
\hline Year of sterilisation & 1980-2005 & 1980-2005 \\
\hline Occupation & $\begin{array}{l}19 \text { house wives; } 6 \text { waged } \\
\text { employees }\end{array}$ & $\begin{array}{l}7 \text { house wives; } 17 \text { beedi } \\
\text { workers; } 1 \text { other work }\end{array}$ \\
\hline Husband a migrant to Middle East & Eight & One \\
\hline
\end{tabular}

\section{Results}

\section{Results from multilevel ordered logit model}

The objective of this analysis was to find out whether or not women belonging to 1986-1991 and 1992-1997 sterilisation cohorts have improved their educational levels since they have been sterilised. Table 2 provides proportional odds ratios, confidence intervals and random intercepts for the five models in each sterilisation cohort.

\section{6-1991 sterilisation cohort}

In this cohort, among women who have been sterilised before 25 years of age, the proportional odds ratios of education in 1998-1999 and 2005-2006 were 1.051 (95\% CI 0.861-1.282) and 1.134 (95 \% CI 0.936-1.374), respectively. This means compared to 1992-1993, the proportional odds ratio of combined primary and secondary education was 1.051 times higher in 1998-1999 and 1.134 times in 2005-2006. For women who were sterilised in the age group 25-29 years the proportional odds ratio of education in 1998-1999 was 0.954 (95\% CI 0.764-1.193) and 1.116 (95\% CI 0.901-1.382) in 2005-2006. For women who have been sterilised at 30 years or above, the proportional odds ratio was 1.001 (95\% CI 0.724-1.138) in 1998 and 1.046 (95\% CI 0.691-1.586) in 2005-2006. For women who have been sterilised with 1-2 children, the proportional odds ratio of education was 0.889 (95\% CI 0.688-1.150) in 1998-1999 and 1.084 (95\% CI $0.853-1.377$ ) in 2005-2006. Further, for women who have been sterilised with 3 or more children, the proportional odds ratio of education was 1.022 (95\% CI $0.859-1.216$ ) in 1998-1999 and 1.143 (95 \% CI 0.970-1.348) in 2005-2006. Thus, in all the five models there was no statistically significant increase in the 
proportional odds ratios of education in 1998-1999 or 2005-2006 compared to the reference year 1992-1993. In all the groups, except for the group with 3 or more children, the estimated variance and standard error suggests that there is no significant variation in women's education across villages (Table 3).

\section{2-1997 sterilisation cohort}

In this sterilisation cohort, for women who have been sterilised at age below 25 years, the proportional odds ratio of education was 0.967 (95\% CI 0.814-1.149) in 2005-2006. The corresponding proportional odds ratio for women who have been sterilised at 25-29 years was 1.107 (0.814-1.505). For women who have been sterilised at 30 years or above, the proportional odds ratio was 1.583 (95\% CI 0.996-2.514). Further, for women who have been sterilised with 1-2 children the proportional odds ratio of education was 1.186 (95\% CI 0.860-1.634) in 2005-2006. The corresponding proportional odds ratio for the women who were sterilised with 3 or more children was 0.969 (95\% CI 0.812-1.557). Thus, there was no statistically significant increase in the proportional odds ratio of women's education in all the five groups. The analysis also revealed no significant variation across villages in all the groups except the group in which women have been sterilised with 3 or more children.

\section{Results from qualitative data}

The quantitative data from South India clearly demonstrated that reproduction-free time provided by female sterilisation and low fertility did not help women to improve their educational levels in India. However, as the data used for this analysis were from cross sectional surveys using pseudo-cohorts, the findings can only be considered indicative. Further this analysis was restricted by the non-availability of some of the key variables that may have hindered women from improving their formal education or skill development. Therefore, this part of the analysis aims to provide context in terms of factors that may have hindered women from utilising the reproduction-free time provided by early age at sterilisation and low fertility for resumption of formal education or skill development.

\section{Female sterilisation in Tamil Nadu and Kerala villages}

In both the villages female sterilisation has been the most common method of family planning. In Tamil Nadu village not only were women sterilised late compared to Kerala village but also had more children at the time of sterilisation. The older cohort of women in Kerala were sterilised between age 30-35 years and with an average of 3 children. The more recent cohorts were sterilised at around 25 years and with an average of 2 children. In Tamil Nadu village, older cohorts were sterilised at around 35 years with an average of four children. In the more recent cohorts average age at sterilisation was around 30 years and with an average of three children. To sterilise at around 25 years and with two children is the most recent trend in the Tamil Nadu village. Thus, this study clearly shows that female 
Table 3 Multilevel ordered logit model for women's education in India

\begin{tabular}{|c|c|c|c|}
\hline \multirow{2}{*}{$\begin{array}{l}\text { Age and parity at } \\
\text { sterilisation }\end{array}$} & \multirow[t]{2}{*}{ Time of survey } & \multicolumn{2}{|l|}{ Sterilisation cohort } \\
\hline & & 1986-1991 & 1992-1997 \\
\hline \multirow{6}{*}{$\begin{array}{l}\text { Model } 1 \\
\text { Sterilised }<25 \text { years }\end{array}$} & Time & & \\
\hline & $1992-1993$ & $\mathrm{R}$ & - \\
\hline & 1998-1999 & $1.051(0.861-1.282)$ & $\mathrm{R}$ \\
\hline & 2005-2006 & $1.134(0.936-1.374)$ & $0.967(0.814-1.149)$ \\
\hline & Individual level & $0.1597(0.7723)$ & $0.000(0.000)$ \\
\hline & PSU level & $0.1464(0.0765)$ & $0.1232(0.0674)$ \\
\hline \multirow{6}{*}{$\begin{array}{l}\text { Model } 2 \\
\text { Sterilised between } 25 \\
\quad \text { and } 29 \text { years }\end{array}$} & Time & & \\
\hline & $1992-1993$ & $\mathrm{R}$ & - \\
\hline & 1998-1999 & $0.954(0.764-1.193)$ & $\mathrm{R}$ \\
\hline & 2005-2006 & $1.116(0.901-1.382)$ & $1.107(0.814-1.505)$ \\
\hline & Individual level & $0.0000(0.0002)$ & $1.5661(3.0456)$ \\
\hline & PSU level & $0.0687(0.0998)$ & $0.2021(0.2099)$ \\
\hline \multirow{6}{*}{$\begin{array}{l}\text { Model } 3 \\
\quad \text { Sterilised } \geq 30 \text { years }\end{array}$} & Time & & \\
\hline & $1992-1993$ & $\mathrm{R}$ & - \\
\hline & 1998-1999 & $1.001(0.724-1.138)$ & $\mathrm{R}$ \\
\hline & 2005-2006 & $1.046(0.691-1.586)$ & $1.583(0.996-2.514)$ \\
\hline & Individual level & $0.0000(0.0007)$ & $0.3419(1.8425)$ \\
\hline & PSU level & $0.2630(0.2217)$ & $0.4637(0.4701)$ \\
\hline \multirow{6}{*}{$\begin{array}{l}\text { Model } 4 \\
\text { Sterilised with 1-2 } \\
\text { children }\end{array}$} & Time & & \\
\hline & 1992-1993 & $\mathrm{R}$ & - \\
\hline & 1998-1999 & $0.889(0.688-1.150)$ & $\mathrm{R}$ \\
\hline & $2005-2006$ & $1.084(0.853-1.377)$ & $1.186(0.860-1.634)$ \\
\hline & Individual level & $0.0000(0.0000)$ & $4.6940414(3.8427974)$ \\
\hline & PSU level & $0.3966(1.1342)$ & $20536065(.22600577)$ \\
\hline \multirow{6}{*}{$\begin{array}{l}\text { Model } 5 \\
\text { Sterilised with } 3 \text { or } \\
\text { more chi }\end{array}$} & Time & & \\
\hline & 1992-1993 & $\mathrm{R}$ & - \\
\hline & 1998-1999 & $1.022(0.859-1.216)$ & $\mathrm{R}$ \\
\hline & 2005-2006 & $1.143(0.970-1.348)$ & $0.969(0.812-1.557)$ \\
\hline & Individual level & $0.0000(0.0014)$ & $0.0000(0.0000)$ \\
\hline & PSU level & $0.1983(0.0608)$ & $0.1883(0.0741)$ \\
\hline
\end{tabular}

Variables included as covariates are: age at marriage, caste, religion, husband's education, and age at sterilisation/parity

$R$ Reference category

age at sterilisation is declining and it is occurring with around two children. At the time of fieldwork, the reproductive norm in the two villages was to have two children and sterilise at around 25 years. Temporary family planning use before sterilisation was uncommon in both the villages as reported in other studies (Dharmalingam 1995; Pallikadavath and Wilson 2005). 
With regard to education, women from the Kerala village had substantially higher levels compared to women in Tamil Nadu village. The majority of women from the younger cohort interviewed in Kerala village had a degree or professional qualification. But majority of the women from the older cohort had only secondary schooling. In Tamil Nadu village the older cohort of women had no education or very low education. However, the most recent cohorts had secondary level education; only few have a degree or higher educational qualifications. Thus, higher education is still not very common among women in the Tamil Nadu village compared to the Kerala village.

In both Kerala and Tamil Nadu villages none of the women we interviewed in this study had resumed formal education after undergoing sterilisation and completing childcare responsibilities. Only one woman in this study reported undertaking skill development training after sterilisation and completing child care responsibilities. Thus, the qualitative data also support the findings from the quantitative analysis that female sterilisation and subsequent cessation of childcare responsibilities did not help women to improve their formal education or skill development. In the following section we discuss barriers that existed at individual, household and community levels that prevented women from improving formal education and/or skill development.

\section{Individual factors}

Table 4 provides results of the thematic analysis of individual level factors associated with women's education and skill development. The individual level themes that were identified include: existing levels of education; perceptions about the right age for study; lack of interest in education; and work status.

Table 4 Individual level themes influencing women's education/skill development after completing childbearing, Kerala and Tamil Nadu, 2011

\begin{tabular}{lll}
\hline Themes & Tamil Nadu & Kerala \\
\hline Poor educational levels are a barrier for women to resume formal education & $\sqrt{ } \sqrt{ }$ & $\sqrt{ }$ \\
Educational level is a barrier for women to undertake skill development & $\sqrt{ } \sqrt{ }$ & $\sqrt{ }$ \\
Age is a barrier for women to resume formal education & $\sqrt{ } \sqrt{ }$ & $\sqrt{ }$ \\
Age is a barrier for women to undertake skill development & $\sqrt{ }$ & $\sqrt{ }$ \\
Change in social status of women within family after sterilisation is a barrier & $\sqrt{ }$ \\
for women to resume education or skill development & $\sqrt{ } \sqrt{ }$ \\
Working women consider resuming formal education or skill development \\
training less useful to their current job \\
Non-working women consider resuming education or skill development not \\
important as there is no social pressure to get a job
\end{tabular}

High $(\sqrt{ } \sqrt{ } \sqrt{ })$; Medium $(\sqrt{ } \sqrt{ })$; and Low $(\sqrt{ })$ is based on number of times the theme appeared per interview and judgement of the importance of this theme as a reason for not undertaking education/skill development 


\section{Existing levels of education}

In Tamil Nadu village, one of the main reasons that women had not been able to return to formal education after sterilisation and child care were the very low levels of education they already possessed. Women who did not have any formal education or very low levels of education did not consider themselves suitable for any formal education. Uneducated women or women with very low levels of education found it inconceivable to consider undertaking formal education. They believed that formal education after childbearing is for those who have already obtained higher qualifications. In the Kerala village the existing educational backgrounds of women were not regarded as a barrier to further education, as the majority of them already possessed secondary or higher education.

In both Kerala and Tamil Nadu villages existing educational levels of women were not considered a barrier to undertaking skill development activities. Indeed women were more comfortable considering skill development training because formal educational qualifications were not required for such training. In Kerala village, women felt that their educational qualifications could be suitable for skill development training in computing and tailoring. Women with lower levels of education from lower socio-economic strata generally preferred tailoring or related training. More highly educated women from higher socioeconomic strata preferred computer-related skill development. In Tamil Nadu village women did not express any specific desire for any particular skill development. This may be because women are overwhelmingly engaged in home-based beedi making (beedi is a thin cigarette made of $0.2-0.3 \mathrm{~g}$ of tobacco flake wrapped in a tendu leaf (Senthil Kumar and Subburethina Bharathi 2010).

In this study the threshold level of existing education needed for women to consider resuming formal education was at least secondary level in Tamil Nadu and a degree qualification in Kerala. No threshold level of education was reported for entering into most of the skill development training. However there were significant social considerations as to what kind of skill development training women would prefer.

\section{Perception about right age for education}

An important individual-level factor that prevented women from pursuing formal education after sterilisation and childcare responsibilities was their perceptions about the right age for formal education. In Tamil Nadu village, women noted that their age was not suitable to return to formal education even if they had time and motivation to do so. Women in their $30 \mathrm{~s}$ considered their age not suitable for formal education as they believed in supporting their children's education. Women in their $40 \mathrm{~s}$ felt that resuming formal education at lower levels, primary or secondary, was totally implausible as these are typically for young people. It is important to note that the majority of the women in this study had functional literacy - they could read and count simple things. Therefore, they did not perceive any gains from resuming primary or secondary education. 
In the Kerala village, age was not considered a barrier to the resumption of formal education or skill development. Women in Kerala reported that for education there is no age limit-people can study at any age. They pointed out that age-related social and economic responsibilities often act as barriers for women undertaking formal education. Clearly, the situation in Kerala reflects higher levels of female education and higher autonomy that women enjoy in this village.

\section{Changes in social status within family}

In the Kerala village, women reported changes in their status within the family after undergoing sterilisation and cessation of childbearing. They reported increased decision-making autonomy in the household (Pallikadavath et al. 2012). They reported that as a result of sterilisation their status in the household is akin to that of their mothers-in-law. Women found their new roles in conflict with their own education. They perceived themselves as mature women in charge of the family, with many responsibilities. A key responsibility that women in Kerala shouldered is children's education. This role is very difficult to fulfil when women themselves are in formal education, particularly in families where husbands work outside the country or state.

In the Tamil Nadu village, on the other hand, changes in women's social status associated with sterilisation increased their economic responsibility in the family. Increased status means women are on par with their mothers-in-law and husbands in responsibility for the economic security of the family. Thus, the increased autonomy of women in the family was a barrier to resuming formal education or skill development. In Tamil Nadu, however, the added responsibility could create demand for skill development training in areas that could provide higher economic returns to the family.

\section{Work status}

Women who were already working for wages felt that further education would not help them in their current jobs. In the Tamil Nadu village, the majority of the women we interviewed were beedi workers. This is a home-based industry. As remuneration is based on the number of beedies they make, women can choose the number of hours they work each day, depending on their daily circumstances. Women reported that beedi making is the only job women can easily get in their village and further skill development or formal education is unlikely to have any positive impact.

In the Kerala village, only a few women interviewed in this study worked for wages. Those working as agricultural labourers did not consider their job a barrier to education or skill development. Those who did not work, on the other hand, did not perceive the need to undertake further education or skill development in order to get a job, as there is no social pressure for women to be in paid employment. Indeed, unemployment of women was very common in the Kerala village and it is highly unlikely that women will be able to get jobs even with added qualifications. 


\section{Household factors}

Table 5 provides results of a thematic analysis of the household level factors that hinder the resumption of formal education and the uptake of skill development in the post-sterilisation and post-childcare period in the Tamil Nadu and Kerala villages.

\section{Value of wife's contribution to the family}

In the Tamil Nadu village, the value of women's economic contribution to the family income was identified as a barrier to the resumption of formal education. As mentioned earlier, the majority of the women in the Tamil Nadu village were engaged in beedi making. These women from poor families contributed to the household economy and this was vital for the day-to-day running of the family. It may be noted here that beedi making is a regular job and provides some economic security to the family through regular income (Senthil Kumar and Subburethina Bharathi 2010; Government of Tamil Nadu 2012). Most of the women reported that their husbands have irregular jobs and therefore perceived their own jobs as having

Table 5 Household level barriers on women's education/skill development after completing childbearing, Kerala and Tamil Nadu, 2011

\begin{tabular}{lc}
\hline Themes & Tamil Nadu Kerala \\
\hline
\end{tabular}

Themes from women's interview

Economic value of women's contribution to family is a barrier to resume education

Better economic status of the family is a barrier to resume education

Looking after husband's parents is a barrier to resume education

Looking after children's needs is a barrier to resume education

Husband works outside the village

Better economic status of the family is a barrier to resume education

Being a member of a joint family

Not having support from in-laws

Traditional family that never allows women to work outside home

Themes from husband's interviews

My wife is not interested in studies or training

My wife has lot of work at home and therefore no time for studies

My wife is not required to work as we are economically better off

Do not want my wife to work in private sector, happy to work in government jobs

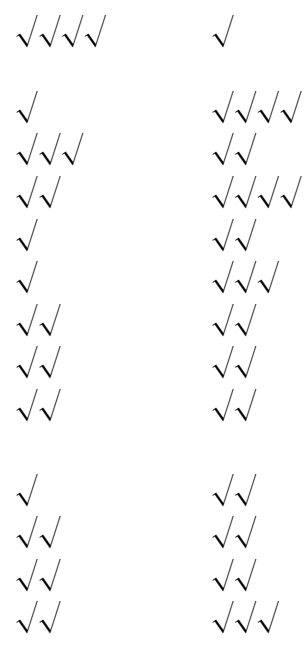

High $(\sqrt{ } \sqrt{ } \sqrt{ })$; Medium $(\sqrt{ } \sqrt{ })$; and Low $(\sqrt{ })$ is based on number of times the theme appeared per interview and judgement of the importance of this theme as a reason for not undertaking education/skill development 
high economic value. In addition to their job women must also perform labour- and time-intensive household activities such as cooking, washing, and cleaning. For most of the women in Tamil Nadu village, the end of childbearing and childcare responsibilities did not diminish household responsibilities. Indeed, the responsibilities of meeting the expenses of education and marriage, besides the immediate daily needs for food and clothing actually increased with the cessation of childbearing. Thus, the economic value of women's work is a hindrance to resuming formal education or undertaking skill development training.

In the Kerala village, on the other hand, women's contribution to the family economy was limited as only very few women worked for wages. Women also reported that their income was not necessary for the day-to-day functioning of the family. In fact women reported that there is social stigma for families that depended solely on women's income. Among younger and more educated couples there is a growing acceptance of joint income-earning and this is now increasingly becoming the preferred household economic model. The perception that the value of women to the family economy is low prevents women from resuming formal education or skill development training in Kerala village.

\section{Economic status of the household}

In the Kerala village women from better-off households did not consider it necessary to return to formal education in order to get a job to support the family. Women in such families bring a large dowry (money or kind transferred from the bride's family to the groom's family at the time of marriage) that is often considered compensation for income from women's work (Bradley and Pallikadavath 2013). Thus, higher household economic status had a negative impact on women's need to resume formal education. Among poor households, women's work is considered positive but this did not result in resuming education as the prospects of getting a job in Kerala are bleak. Women reported that more women from poorer households would resume formal education if there were jobs that would match the newly acquired qualification or skill.

In the Tamil Nadu village, better-off households valued women's work and contribution to their households and therefore resuming formal education was welcomed. However, they could not see how the newly acquired qualification would help to get a job. Poor households valued women's resumption of education but their current economic contribution to the family was a barrier. There was significant support for skill development among women from poor households in Tamil Nadu village, but within the context of their current engagement in beedi making the need for any other form of skill development was not felt by women in this study.

\section{Value of children}

Two types of families are found in the study villages; child-centred and adultcentred. In child-centred families the focus is to educate children to the best possible levels. Often in such families adults sacrifice their own well-being for their children. 
In adult-centred families the elderly receive better attention from others including children. While child-centred families are more common in the Kerala village, adult-centred joint families were common in the Tamil Nadu village. In the Kerala village women supported their children in every aspect of children's education. For example, in many families women reported that they make sure that they are present when children return from school to provide food and to support homework. Women reported that they could not go out for a full day, as they have to meet the various requirements of their children. In this context women felt that it was difficult to resume formal education. In the Tamil Nadu village women felt greater responsibility for looking after the needs of their husbands, as in the majority of cases they were working locally.

\section{Husbands'views}

Husbands in both Kerala and Tamil Nadu villages recognised their wives' workload at home. Men reported that their wives have no spare time for formal education or training activities. It is important to mention here that women undertake most of the household work even if men have free time. There are significantly gendered roles in the family and certain activities will only be done by women-mainly cooking and household chores such as cleaning and washing. It appears that husbands' recognition of women's role in the family supports fixed gender roles and this seems to hinder women's resumption of formal education and training. Husbands in Kerala reported that their wives need not resume studies as they do not need them to work to support the family. However, in the Tamil Nadu village husbands considered women's contribution important to their family income. Husbands in the Kerala village held the view that their wives are not interested in studies. They maintained that they would be willing to support their wives should they show genuine interest in studies. In both Kerala and Tamil Nadu villages, husbands were not willing to allow their wives to work in the private sector, particularly in service industries. They also reported that as there are no government jobs there is no benefit in resuming education. It may be noted that women can take up jobs in the service sector without further education and training.

\section{Community factors}

Table 6 provides results of a thematic analysis of community level factors that hindered the resumption of formal education and uptake of skill development in the post-sterilisation and post-childcare period in the Tamil Nadu and Kerala villages.

\section{Tradition}

In both Kerala and Tamil Nadu villages, women are traditionally married after completing their education to a level felt appropriate to the family status. Generally, women never resume studies after marriage. In recent years, women in the Kerala village have continued higher education after marriage when their marriages took 
Table 6 Community level themes influencing women's education/skill development after completing childbearing, Kerala and Tamil Nadu, 2011

\begin{tabular}{lll}
\hline Themes & Tamil Nadu & Kerala \\
\hline $\begin{array}{l}\text { In the village women traditionally do not resume formal education after having } \\
\text { children (W,H,L,C) }\end{array}$ & $\sqrt{ } \sqrt{ }$ & $\sqrt{ } \sqrt{ }$ \\
Lack of employment opportunities for women in this area is a barrier for & $\sqrt{ }$ & $\sqrt{ }$ \\
women to resume formal education or skill development (W,H,L,C) & $\sqrt{ }$ \\
Lack of skill development training facilities in the village or nearby places is a & $\sqrt{ }$ \\
barrier for women to undertake skill development training (W,H,L,C) & \\
$\begin{array}{l}\text { Lack of colleges/training institutions in the village or nearby places is a barrier } \\
\text { for women to resume formal education (W,H,C) }\end{array}$ & $\sqrt{ } \sqrt{ }$ \\
$\begin{array}{l}\text { Lack of women-friendly transport services are a barrier for women to travel } \\
\text { for skill development training (W,H,L,C) }\end{array}$ & $\sqrt{ } \sqrt{ }$ \\
$\begin{array}{l}\text { Families that send married women for education or skill development are } \\
\text { looked down on in the village }\end{array}$ & $\sqrt{ } \sqrt{ }$
\end{tabular}

High $(\sqrt{ } \sqrt{ } \sqrt{ })$; Medium $(\sqrt{ } \sqrt{ })$; and Low $(\sqrt{ })$ is based on number of times the theme appeared per interview and judgement of the importance of this theme as a reason for not undertaking education/skill development

$W$ Wife, $H$ Husband, $L$ In-laws, $C$ community members

place during their studies. But resuming education at any level after completing childbearing was not reported among the women interviewed in this study. Women reported that there is very little support from the community for women to resume education or to undertake a training course because such activities are seen as an act of deviant behaviour. In the Kerala context, young wives of migrants have reported social problems if they pursue studies or training courses as villagers gossip about their extra-marital relationships which in turn can lead to family problems. Women reported that such actions contravene social norms and husbands or other family members are often blamed.

Women also reported that if married women resume education or undertake any skill development training it is a clear signal that their economic situation is deteriorating and that they need financial support. As husbands and other members of the family do not like to be looked down upon by their neighbours, women are generally not encouraged to resume education or undertake training to avoid such embarrassment. Such perception was greater in Kerala village compared to Tamil Nadu village. Thus, in both Tamil Nadu and Kerala villages, there is a widespread view that education prepares women for a better marriage and once that is achieved, education does not have further value in women's lives.

\section{Lack of employment opportunities}

An important factor that women, husbands, and in-laws considered a reason for women not to resume formal education after sterilisation and cessation of childbearing is the lack of employment opportunities. In both Kerala and Tamil Nadu village employment opportunities in the village are limited to agriculture and construction-related work. Government sector jobs are very few and must be 
obtained through national- or state-level competitive tests. The major employers in the village and neighbouring cities are mainly shops and educational establishments. There are no industries in and around the villages.

\section{Lack of educational/training institutions}

The majority of the educational institutions in and around the two villages of Kerala and Tamil Nadu mainly offer secondary level education. Colleges and technical educational institutions were located in cities. However, in Kerala village women were able to gain training in computing and tailoring in the village from private providers, which are located in nearby towns or in some cases within the village. In Tamil Nadu village no such provision was available for women in the village.

\section{Admission policies in educational and training institutions}

In government or aided educational institutions admission policies are based on academic performance (there are quotas for socio-economically disadvantaged groups and certain other categories) and do not take into account interruptions in education or personal circumstances. Women reported that they cannot compete with next generation children as they have higher marks and are better equipped to undertake competitive tests for admission.

\section{Lack of women-friendly transport facilities}

In Tamil Nadu village transport to the nearest city was mainly through public bus services. Many householders must walk long distances to the nearest bus stop. A long wait for buses to the nearest town was reported by women. They also reported concerns about safety in getting back home late in the evening and at night. Women reported that they find it difficult to go on their own to town for any training for these reasons. In Kerala the public transport system was far better than in Tamil Nadu village in terms of access to services, number of stops, frequency and punctuality of services. However, women reported concerns in travelling alone at night.

\section{Discussion}

This is perhaps the first study that examined the impact of early age at sterilisation and low fertility on women's educational and skill development in a developing country context. Using three rounds of National Family Health Survey (NFHS) data and qualitative data collected from Tamil Nadu and Kerala, this paper examined whether early age at sterilisation and low fertility enabled women to resume formal education or skill development in the post-sterilisation period. The quantitative component of the study revealed that, in South India, having fewer children and sterilisation at younger ages did not help women resume formal education or acquire skills through formal or informal training. 
To investigate factors that have hindered women's resumption of formal education or participation in formal or informal skill development, qualitative data were collected from women who have been sterilised and completed their child care responsibilities, their husbands, their in-laws and community members. Qualitative data confirmed the findings of the quantitative data analysis; none of the women in the qualitative study had resumed formal education after sterilisation and completing childcare responsibilities, and only one woman had undertaken skill development training. Broadly, factors that hindered women's participation in education or skill development after sterilisation included individual-, householdand community-level factors, and macro-level policies.

Individual factors such as women's existing educational levels and age were important factors that hindered women from resuming formal education. Poor educational attainment was a self-limiting factor. In order to encourage women to resume formal education after childbearing there is a need to increase the threshold level of education to a minimum of 12 years. Higher threshold levels of education are needed in contexts where prevailing overall educational levels are higher. In general, women are more likely to have positive attitudes towards the resumption of formal education when they already have a degree qualification. Thus, the benefits of early age at sterilisation and low fertility can only lead to the resumption of formal education if women have a threshold level of education that is appropriate to the prevailing educational level of the community in which they live. In Kerala, for example, a higher threshold level is required compared to Tamil Nadu for women to feel confident to resume formal education. A study carried out among US women in 1970 showed that women who had higher education at marriage had higher postnuptial education (Davis and Bumpass 1976). Thus, policies that encourage women to resume formal education in the post-sterilisation period need to take into account the prevailing educational levels of women. Given low levels of education among women and high illiteracy [about $35 \%$ women are illiterate according to the 2011 census (Census of India 2012)] in India, there is a need to improve basic educational levels before any benefits of sterilisation and low fertility are realised.

Prevailing attitudes dictate that women are expected to complete their general education by 20 years of age and to be married soon after. Higher ages limits were granted for advanced studies such as postgraduate or professional studies. As the majority of women undergo sterilisation at 25-30 years and are free from child care responsibilities by age 30-35 years, they are outside the normative age range for a formal education. Thus, prevailing social norms about the 'right' age for formal education are likely to hinder women from resuming formal education. While there are no age restrictions for enrolling in a study program, there is an upper age limit for government jobs. Although some initiatives have been taken by various state governments (TNN 2012; JagramJosh 2012) to increase the maximum age for government jobs, there is a need to remove age restrictions altogether in all jobs nationally.

The economic status of the family was an important obstacle to women's ability to resume formal education in the post-sterilisation and -childcare period. Husbands and other family members from better-off households considered women's contribution to the family economy unnecessary and therefore did not consider 
women's education important. Poor households, on the other hand, could not spare women for formal education as their economic contribution to the family was significant. Similar findings were noted in a study carried out in Tamil Nadu where advanced education was more difficult to achieve when the economic situation of the family was poor and especially when they faced agriculture failures (Kajisa 2010). Husbands in general held the view that women are too important to the family to let them resume formal education. In-laws also believed that women have important family responsibilities including caring for elderly parents.

In this study, population sterilisation and low fertility enabled young daughtersin-law to achieve greater decision making autonomy within the household, often on par with their mothers-in-law (Pallikadavath et al. 2012). However, women felt that this came with greater responsibility. Women from poor households reported that it would be impossible for them to give up their jobs for their own education or training as they shared responsibility for the family. Rich women, on the other hand, felt the need to invest their time in their children, particularly to support them in their education and wellbeing. Thus, increased autonomy did not help women to exploit free time arising as a result of early sterilisation and low fertility.

Community characteristics also hindered women's participation in education in the post-sterilisation and -childbearing period. The tradition that women complete their education before marriage is deeply rooted in community values. There is greater community resistance to women undertaking formal education particularly in households where husbands stay elsewhere for work. The lack of formal educational institutions in the villages or nearby and of women-friendly transport services were significant community level factors identified by women as potential deterrents.

In this study only one woman reported undertaking skill development training and there is significant unmet need for skill development training. This study revealed that women consider skill development training more appropriate than resuming formal education in the post-sterilisation period. Women considered skill development appropriate at any age and level of education. There is greater acceptance by husbands, in-laws, and community members of women seeking vocational skill development training than of resuming formal education in the poststerilisation and -childcare period.

This study highlights the untapped human resource that emerges as a result of time freed by early age at sterilisation and low fertility, and the need to exploit this resource. It is apparent that the pathways to resuming formal education are complex. Change may be achieved incrementally with changes in women's pre-sterilisation education levels and overall development, particularly with regard to transport and a women-friendly educational system, which requires significant policy and attitudinal changes (Morrisson and Jütting 2005). Returns from formal education are higher than from vocational training programs, which may also influence the uptake of formal education (Kahyarara and Teal 2008). The more acceptable and practical approach to the use of women's time is through the creation of an appropriate environment for skill development training that helps women to obtain jobs.

A National Policy on Skill Development was approved by the Indian Cabinet in 2009 to meet the increasing requirement for skilled workers in the existing and 
emerging labour market nationally and internationally. This policy aimed at increasing the participation of youth, women, the disabled and other disadvantaged groups in skill development programs. Several skill development initiatives have been generated by the national government under various Ministries of Government of India. These skill development programs mainly focus on the young, the poor, students, farmers, and those already in a job. Some of the training programs target women but are designed for younger women and women who are already in jobs (Planning Commission 2012). It may be noted that the government is in the process of establishing 5000 Skill Development Centres (SDCs), 1500 Industrial Training Institutions (ITIs), 15 Advanced Training Institutions (AITs) and 12 Regional Vocational Training Institutions for Women (RVTIs) announced by the Prime Minister in 2007 (Government of India 2011). There is a great deal of interest within the new government of 2014 in increasing higher education institutions in India. In general, existing skill development facilities in India are inadequate to meet the skill development needs of women. No skill development programs to date target women who have completed their childbearing and childcare responsibilities, who are typically 35 years and above. It is important that the new government and the National Skill Development Corporation take into account the training needs of women who have completed their childbearing responsibilities. These women have the desire to take up jobs and have the potential to contribute to the economy. This important demographic dividend will be lost if governments fail to take steps to maximise the potential contribution of this numerically significant population. As a State Council for Skill Development and State Skill Development Board are also being established it is an appropriate time to assess various state-specific needs, particularly of women who have completed their childbearing and child care responsibilities.

Open Access This article is distributed under the terms of the Creative Commons Attribution 4.0 International License (http://creativecommons.org/licenses/by/4.0/), which permits unrestricted use, distribution, and reproduction in any medium, provided you give appropriate credit to the original author(s) and the source, provide a link to the Creative Commons license, and indicate if changes were made.

\section{References}

Basu, A. (1985). Family planning and the emergency: an unanticipated consequence. Economic and Political Weekly, 20(10), 422-425.

BBC News South Asia. (2011). India: Rajasthan in 'cars for sterilisation'. http://www.bbc.co.uk/news/ world-south-asia-13982031. Accessed 21 March 2016.

Bhandari, R., \& Smith, F. J. (1997). Rural women in India: Assessment of educational constraints and the need for new educational approaches. Journal of Research in Rural Education, 13(3), 183-196.

Bradley, T., \& Pallikadavath, S. (2013). Dowry and women's lives in Kerala: What has changed in a decade? Contemporary South Asia, 21(4), 444-461.

Brannen, J. (2005). Mixed methods research: A discussion paper. ESRC National Centre for Research Methods.

Census of India. (2012). Literacy rates, 7+ yrs. Final Population Tables. http://www.dataforall.org/ dashboard/censusinfoindia_pca/. Accessed 23 March 2016.

Cleland, J. (2009). Contraception in historical and global perspective. Best Practice and Research Clinical Obstetrics and Gynaecology, 23, 165-176. 
Cleland, J., Conde-Agudelo, A., Peterson, H., Ross, J., \& Tsui, A. (2012). Contraception and health. Lancet, 380(9837), 149-156.

Davis, J., \& Bumpass, L. (1976). The continuation of education after marriage among women in the US: 1970. Demography, 13(2), 161-174.

Dharmalingam, A. (1995). The social context of family planning in a south indian village. International Family Planning Perspectives, 21, 98-103.

Donaldson, P. (2002). The elimination of contraceptive acceptor targets and the evolution of population policy in India. Population Studies, 56(1), 97-110. doi:10.1080/00324720213793.

Dreze, J., \& Murthi, M. (2001). Fertility, education, and development: Evidence from India. Populaiton and Development Review, 27(1), 33-63.

Goldstein, H. (2010). Multilevel statistical models (4th ed.). Chicester, GB: Wiley.

Government of India. (2011). Second annual report to the people on employment. New Delhi: Ministry of Labour and Employment.

Government of India. (2012). Pathanamthitta district. http://pathanamthitta.nic.in/Administration1.htm. Accessed 15 January 2013.

Government of Tamil Nadu. (2012). Tamil Nadu Government Gazette. http://www.tn.gov.in/ stationeryprinting/extraordinary/2012/256-Ex-II-2.pdf.

Gwatkin, D. (1979). Political will and family planning: the implications of India's emergency experience. Population and Development Review, 5(5), 29-59.

International Institute for Population Sciences (IIPS). (1995). National Family Health Survey (MCH and Family Planning), India 1992-93. Bomaby: IIPS.

International Institute for Population Sciences (IIPS) and Macro International. (2007). National Family Health Survey (NFHS-3), 2005-06. http://pdf.usaid.gov/pdf_docs/PNADK385.pdf. Accessed 14 May 2012.

International Institute for Population Sciences (IIPS) and ORC Macro. (2000). National Family Health Survey (NFHS-2) 1998-99: India. Mumbai: IIPS.

JagranJosh. (2012). Uttarakhand Cabinet raised Maximum Age limit to 40 Years for Government Jobs. http://www.jagranjosh.com/current-affairs/uttarakhand-cabinet-raised-maximum-age-limit-to-40years-for-government-jobs-1345630623-1. Accessed 22 March 2016.

Kahyarara, G., \& Teal, F. (2008). The returns to vocational training and academic education: Evidence from Tanzania. World Development, 36(11), 2223-2242. doi:10.1016/j.worlddev.2007.11.011.

Kajisa, K. (2010). Schooling investments over three decades in rural Tamil Nadu, India: Changing effects of income, gender, and adult family members' education. World Development, 38(3), 298-314.

Krishnakumar, S. (1974). Ernakulam's third vasectomy campaign using the camp approach. Studies in Family Planning, 5(2), 58-61.

Ledbetter, R. (1984). Thirty years of family planning in India. Asian Survey, 24(7), 736-758.

McNay, K., Arokiasamy, P., \& Cassen, R. (2003). Why are uneducated women in India using contraception? A multilevel analysis. Population Studies, 57(1), 21-40.

Morrisson, C., \& Jütting, J. P. (2005). Women's discrimination in developing countries: A new data set for better policies. World Development, 33(7), 1065-1081. doi:10.1016/j.worlddev.2005.04.002.

National Informatics Centre. (2013). Tirunelveli District. http://www.nellai.tn.nic.in/.

National Population Stabilisation Fund. (2007). Why is it that fewer couples opt for male sterilization? http://www.jsk.gov.in/faq.asp\#b24. Accessed 14 May 2012.

One India. (2011). God's own country on male sterilisation drive. http://news.oneindia.in/2011/06/27/ gods-own-country-on-male-sterilization-drive-aid0113.html. Accessed 22 March 2016.

Pallikadavath, S., Rajan, I., Singh, A., \& Ogollah, R. (2012). Post-sterilization autonomy among young mothers in South India. Portsmouth: University of Portsmouth.

Pallikadavath, S., \& Wilson, C. (2005). Paradox within a paradox: the fertility of the lower caste in Kerala. Economic and Political Weekly, 40(28), 3085-3093.

Planning Commission. (2012). Skill development and training programmes of central governments. http:// planningcommission.gov.in/reports/genrep/skilldev/rep_skilldev8.pdf.

QSRInternational. (2010). NVivo 9.

Rajna, P., Kulkarni, P., \& Thenmozhi, N. (2005). Fertility in Tamil Nadu: Levels and recent trends. In C. Guilmoto \& S. I. Rajan (Eds.), Fertility transition in South India. Thousand Oaks: Sage Publications Ltd.

Ross, J., \& Smith, E. (2011). Trends in national family planning programs, 1999, 2004 and 2009. International Perspectives on Sexual and Reproductive Health, 37(3), 125-133.

Seletzer, R. (2002). Family planning in developing countries. Pittsburgh: RAND. 
Senthil Kumar, N., \& Subburethina Bharathi, P. (2010). A study on occupational hazards among women beedi rollers in Tamilnadu, India. International Journal of Current Research, 11, 117-122.

Singh, A., Ogollah, R., Ram, F., \& Pallikadavath, S. (2012). Sterilization regret among married women in India: Implications for the Indian National Family Planning Program. International Perspectives on Sexual and Reproductive Health, 38(4), 187-195. doi:10.1363/3818712.

Srinivasan, K. (1998). Population policies and programmes since independence: a saga of great expectations and poor performances. Demography India, 27(1), 1-22.

StataCorp. (2009). Stata statistical software 11. College Station, TX: Stata Corp LP.

Times News Network. (2012). Age limit for government jobs relaxed. Times of India. Rajkot. http:// timesofindia.indiatimes.com/city/rajkot/Age-limit-for-govt-jobs-relaxed/articleshow/16439705.cms. Accessed 23 March 2016.

United Nations. (2011). World Contraceptive Use 2011. http://www.un.org/esa/population/publications/ contraceptive2011/wallchart_front.pdf. Accessed May 122012. 